\title{
Attenuated Ochratoxin A Transporter Expression in a Mouse Model of Nonalcoholic Steatohepatitis Protects against Proximal Convoluted Tubule Toxicity.
}

Joseph L. Jilek, Kayla L. Frost, Solène Marie, Cassandra M. Myers, Michael Goedken, Stephen H. Wright, Nathan J. Cherrington

Department of Pharmacology \& Toxicology, University of Arizona, College of Pharmacy, Tucson AZ (J.L.J., K.L.F., S.M., C.M.M., N.J.C.)

Rutgers Translational Sciences, Rutgers University, Piscataway, NJ (M.G.)

Department of Physiology, University of Arizona, College of Medicine, Tucson AZ (S.H.W.) 


\section{Running Title Page}

Running Title: NASH increases ochratoxin A renal excretion

\section{Corresponding Author:}

Nathan J. Cherrington, PhD

331B Skaggs Pharmaceutical Sciences Building, 1703 E Mabel St, Tucson, AZ 85724

Telephone: (520) 626-0219

Fax: (520) 626-6944

cherrington@pharmacy.arizona.edu

\section{Number of text pages: 18}

Number of tables: 2

Number of figures: 6

Number of references: 51

Number of words in the abstract: 249

Number of words in the introduction: 987

Number of words in the discussion: 807

Abbreviations: AUC, area under the plasma concentration-time curve; $\mathrm{CL}$, clearance; FFD/TH, fast food diet with thioacetamide; LC-MS/MS, liquid chromatography-tandem mass spectrometry; MRP, multidrug resistance-associated protein; NAFLD, nonalcoholic fatty liver disease; NASH, nonalcoholic steatohepatitis; OAT, organic anion transporter; OATP, organic 
anion transporting polypeptide; OTA, ochratoxin $A ; t_{1 / 2}$ elimination half-life; $V$, volume of distribution.

\section{Abstract}

Ochratoxin A (OTA) is an abundant mycotoxin, yet the toxicological impact of its disposition is not well studied. OTA is an organic anion transporter (OAT) substrate primarily excreted in urine despite a long half-life and extensive protein binding. Altered renal transporter expression during disease, including nonalcoholic steatohepatitis (NASH), may influence response to OTA exposure, but the impact of NASH on OTA toxicokinetics, tissue distribution, and associated nephrotoxicity are unknown. By inducing NASH in fast food-dieted/thioacetamide-exposed mice, we evaluated the effect of NASH on a bolus OTA exposure (12.5 mg/kg p.o.) after 3 days. NASH mice presented with less gross toxicity (44\% less bodyweight loss) and kidney and liver weights of NASH mice were $11 \%$ and $24 \%$, respectively, higher than healthy mice. Organ and body weight changes coincided with reduced renal proximal tubule cells vacuolation, degeneration and necrosis though no OTA-induced hepatic lesions were found. OTA systemic exposure in NASH mice increased modestly from $5.65 \pm 1.10$ to $7.95 \pm 0.61 \mathrm{mg}{ }^{\star} \mathrm{h} / \mathrm{mL} / \mathrm{kg} \mathrm{BW}$, renal excretion increased robustly from $5.55 \pm 0.37 \%$ to $13.11 \pm 3.10 \%$, relative to healthy mice. Total urinary excretion of OTA increased from $24.41 \pm 1.74$ to $40.07 \pm 9.19 \mu \mathrm{g}$ in NASH mice and kidney-bound OTA decreased $\sim 30 \%$. Renal OAT isoform expression (OAT1-5) in NASH mice decreasd by $\sim 50 \%$ with reduced OTA uptake by proximal convoluted cells. These data suggest that $\mathrm{NASH}$-induced OAT transporter reductions attenuate renal secretion and reabsorption of OTA, increasing OTA urinary excretion and reducing renal exposure, thereby reducing nephrotoxicity in $\mathrm{NASH}$.

\section{Significance Statement}


These data suggest a disease-mediated transporter mechanism of altered tissue-specific toxicity following mycotoxin exposure, despite minimal systemic changes to OTA concentrations. Further studies are warranted to evaluate the clinical relevance of this functional model and the potential effect of human NASH on OTA and other organic anion substrate toxicity.

\section{Introduction}

Since the discovery of ochratoxin A (OTA) in 1965 (van der Merwe, Steyn, Fourie, Scott and Theron, 1965), the specific molecular mechanism of toxicity has yet to be determined (Malir, Ostry, Pfohl-Leszkowicz, Malir and Toman, 2016). OTA is a well-known mycotoxin that primarily contaminates foodstuffs, which serve as the primary route of exposure (Santos, Marín, Sanchis and Ramos, 2009; Palumbo, O'Keeffe, Ho and Santillan, 2015; Malir, Ostry, Pfohl-Leszkowicz, Malir and Toman, 2016). Ochratoxins are naturally occurring metabolites produced by several fungi, including Aspergillus and Penicillium species, although OTA is considered the most toxic of the group (Bui-Klimke and Wu, 2015). Epidemiological studies have linked OTA exposure to Balkan endemic nephropathy (Castegnaro, Canadas, Vrabcheva, Petkova-Bocharova, Chernozemsky and Pfohl-Leszkowicz, 2006; Yordanova, Wilfried, Tsolova and Dimitrov, 2010), demonstrating that the kidney may be a target organ of toxicity. Indeed, given the prevalence of OTA in contaminated and spoiled foodstuffs, nephrotoxicity is a common finding in many animal species exposed to OTA, in addition to humans (Huff, Wyatt and Hamilton, 1975; Mally, Völkel, Amberg, Kurz, Wanek, Eder, Hard and Dekant, 2005; Heussner and Bingle, 2015). Many mechanisms of toxic action have been proposed to explain OTA-induced renal damage (Simon, Godin and Fillastre, 1996) including apoptosis induction and reduced proximal tubule cell adhesion, metabolism dysregulation, disruption of cellular electrochemical and $\mathrm{pH}$ homeostasis, and inducing oxidative stress (Gekle and Silbernagl, 1993; Gekle, Pollock and Silbernagl, 1995; Schwerdt, Freudinger, Mildenberger, Silbernagl and Gekle, 1999; Limonciel and Jennings, 
2014). Though most evidence suggests that OTA selectively damages proximal convoluted tubule epithelial cells, glomerular changes may accompany chronic OTA exposure, (Gekle and Silbernagl, 1994). Furthermore, OTA is an immunotoxicant (Al-Anati and Petzinger, 2006), and is also genotoxic in multiple species, including humans, necessitating the need for enhanced understanding of chronic exposure (Pfohl-Leszkowicz and Manderville, 2007; Stoev, 2010).

Toxicokinetic properties of xenobiotics are common variables in drug disposition and toxicity because slower drug clearance may exacerbate toxicity by increasing exposure. Furthermore, changes to systemic exposure may not always predict target organ toxicity, as transportmediated uptake may concentrate certain toxicants into specific organs due to transporter isoform distribution and substrate specificity (Shitara, Horie and Sugiyama, 2006; Hagos and Wolff, 2010). As a major xenobiotic clearance organ, the kidney expresses many specific transporters along the length of the nephron. Specifically, several organic anion transporter (OAT) isoforms are heavily expressed in proximal convoluted tubule cells of the renal cortex, where most xenobiotic active secretion and reabsorption from filtrate occurs (Masereeuw and Russel, 2001). Namely, OAT1 and 3 are expressed on the basolateral (blood) side, and although both are functionally bi-directional, they predominately import endogenous and exogenous solutes in coupled exchange for intracellular a-ketoglutarate (Nigam, Bush, Martovetsky, Ahn, Liu, Richard, Bhatnagar and Wu, 2015; Ivanyuk, Livio, Biollaz and Buclin, 2017; Huo and Liu, 2018). OTA is negatively charged at physiological $\mathrm{pH}$ and is a known substrate for OAT1 and 3 (Jung, Takeda, Kim, Tojo, Narikawa, Yoo, Hosoyamada, Cha, Sekine and Endou, 2001). Apical efflux of organic anions, including OTA, may be facilitated by transepithelial transport mediated by multidrug resistance-associated proteins (MRP) isoforms, including MRP2 and 4 and breast cancer resistance protein (BCRP), which efflux substrates into the renal filtrate (Anzai, Jutabha and Endou, 2010). While these processes are unidirectional, apical OAT isoforms (Oat2 and 5 in rodents and OAT4 in humans) may also remove organic 
anion solutes from the filtrate, reabsorbing them back into the proximal tubule cell (Cha, Sekine, Kusuhara, Yu, Kim, Kim, Sugiyama, Kanai and Endou, 2000; Youngblood and Sweet, 2004; Anzai, Jutabha, Enomoto, Yokoyama, Nonoguchi, Hirata, Shiraya, He, Cha, Takeda, Miyazaki, Sakata, Tomita, Igarashi, Kanai and Endou, 2005; Shima, Komori, Taylor, Stryke, Kawamoto, Johns, Carlson, Ferrin and Giacomini, 2010). Taken together, OTA renal elimination is a sum of OAT1/3-mediated secretion into the proximal convoluted tubule cell, efflux via MRP isoforms into the filtrate, passive filtration of the small amount unbound in plasma through the glomerulus, and any reabsorption from the filtrate via OAT2/5 in rodents (OAT4 in humans) (Anzai, Jutabha and Endou, 2010).

Inter-individual variability in transporter expression is a known mediator of variable pharmacokinetics, tissue distribution, and toxicity (Meier, Pauli-Magnus, Zanger, Klein, Schaeffeler, Nussler, Nussler, Eichelbaum, Meier and Stieger, 2006; Prasad, Evers, Gupta, Hop, Salphati, Shukla, Ambudkar and Unadkat, 2014). These changes are often a result of genetic polymorphisms, sex, age, and disease (Urakami, Nakamura, Takahashi, Okuda, Saito, Hashimoto and Inui, 1999; Yonezawa, Masuda, Nishihara, Yano, Katsura and Inui, 2005; Nakanishi and Tamai, 2012; Mooij, Schwarz, de Koning, Leeder, Gaedigk, Samsom, Spaans, van Goudoever, Tibboel, Kim and de Wildt, 2014; Xu, Wang, Lu, Xu, Wu and Liu, 2017). While many of these changes are inherited, disease progression may induce transporter expression changes that are not inherited - or phenoconversion. Specifically, nonalcoholic steatohepatitis (NASH), the progressive and inflammatory stage of nonalcoholic fatty liver disease (NAFLD), has been shown to alter hepatic transporter expression in human and animal models of the disease, including specific organic anion transporting polypeptide (OATP) and MRP isoforms (Hardwick, Fisher, Canet, Scheffer and Cherrington, 2011; Clarke, Hardwick, Lake, Lickteig, Goedken, Klaassen and Cherrington, 2014; Clarke and Cherrington, 2015; Dzierlenga and Cherrington, 2018). Recently, our group has identified specific changes to renal transporters 
during NASH (Canet and Cherrington, 2014; Canet, Hardwick, Lake, Dzierlenga, Clarke, Goedken and Cherrington, 2015; Laho, Clarke, Dzierlenga, Li, Klein, Goedken, Micuda and Cherrington, 2016). Specifically, NASH-mediated changes to renal transporters have been shown to affect the disposition and toxicity of drugs, including renally-cleared cisplatin (Jilek, Frost, Jacobus, He, Toth, Goedken and Cherrington, 2021). However, renal disposition-related changes to the toxicity of organic anion substrates, such as OTA, have not yet been evaluated in an appropriate model.

To further understand changes to organic anion toxicokinetics and downstream effects on nephrotoxicity during $\mathrm{NASH}$, we propose a fast food-dieted mouse with thioacetamide (FFD/TH) model to induce NASH. In this study, we demonstrate that reductions in renal OAT isoforms during NASH lead to increased urinary OTA clearance, and this in turn protects NASH mice from OTA-mediated nephrotoxicity.

\section{Materials and Methods}

\section{Reagents}

OTA and d5-OTA were purchased from Toronto Research Chemicals. Carboxymethyl cellulose, thioacetamide, and sodium deoxycholate were purchased from Sigma Aldrich. LC-MS-grade acetonitrile, water, ethyl acetate, and formic acid were purchased from Fisher Chemical. Sequencing-grade trypsin was purchased from Promega, Inc.

\section{Animal Care and Use}

All procedures were approved by the University of Arizona Institutional Animal Care and Use Committee and were carried out in accordance with the Guide for the Care and Use of Laboratory Animals. Five-week-old male C57BL/6J mice were purchased from Jackson Laboratories (Bar Harbor, ME) and acclimated for one week in polycarbonate cages (3 mice/cage). After acclimation, mice were randomly split into healthy and NASH cohorts: eight 
mice were fed choline sufficient and iron supplemented L-amino acid rodent diet (Dyets Inc., Model No. 518754) to maintain healthy phenotype and eight mice were fed an amino aciddefined fast food diet (Test Diets, Model No. AIN-76A) to induce the NASH phenotype, as previously demonstrated (Sharma, Gupta and Abdullah, 2019). To induce hepatic inflammation consistent with a NASH phenotype, NASH mice were also administered thioacetamide (75 $\mathrm{mg} / \mathrm{kg}$ i.p.) thrice weekly; thioacetamide was formulated at $10 \mathrm{mg} / \mathrm{mL}$ in sterile saline then passed through a $0.2 \mu \mathrm{m}$ filter. Water and test diets were available to mice ad libitum and thioacetamide (for FFT/TH model mice only) was administered for eight weeks to establish disease models.

\section{OTA Exposure, Toxicokinetics, and Disposition}

OTA was diluted to $1.25 \mathrm{mg} / \mathrm{mL}$ in $0.25 \%$ carboxymethyl cellulose in water and then filter sterilized by passing through a $0.2 \mu \mathrm{m}$ filter. Four animals each from healthy and NASH cohorts were administered $12.5 \mathrm{mg} / \mathrm{kg}$ formulated OTA by oral gavage at $\mathrm{t}=0 \mathrm{~h}$ and then placed into metabolic cages; another four animals from each group were not exposed to OTA and maintained as toxicant-naïve cohorts. After exposure, approximately $10 \mu \mathrm{L}$ of whole blood was collected by submandibular venipuncture into heparinized tubes at $\mathrm{t}=0.5,1,2,3,6,12,24$, and $48 \mathrm{~h}$ post-dose and then centrifuged for $15 \mathrm{~min}$ at $4{ }^{\circ} \mathrm{C}$ and $2,000 \times \mathrm{g}$ to separate plasma. Urine was collected at $6,24,48$, and $72 \mathrm{~h}$ post-dose by rinsing the metabolic cage with $\sim 5 \mathrm{~mL}$ of water to collect any urine that dried onto the metabolic cage funnel. At $8 \mathrm{~h}$ post-dose, mice were administered subcutaneous sterile saline $(10 \mathrm{~mL} / \mathrm{kg})$ to account for repeated blood loss at early timepoints. At $72 \mathrm{~h}$ post-dose, animals were sacrificed by carbon dioxide overdose and terminal blood was collected into heparinized needles by cardiac puncture. Kidney and liver tissues were collected and snap frozen in liquid nitrogen; a small slice of both tissues was preserved in 10\% neutral buffered formalin prior to dehydration and embedding in paraffin for histopathology. All plasma, urine, and tissue samples were stored at $-80{ }^{\circ} \mathrm{C}$ until processed. Hematoxylin- and 
eosin-stained tissue sections were scored for the following by a board-certified veterinary pathologist: renal necrosis, degeneration, regeneration, proximal tubule vacuolation, tubule dilation, epithelial cell loss, and glomerular change; hepatic lipid accumulation, necrosis, apoptosis, inflammation, fibrosis, and biliary hyperplasia as previously described (Laho, Clarke, Dzierlenga, Li, Klein, Goedken, Micuda and Cherrington, 2016).

\section{LC-MS/MS Measurement of OTA}

Pure OTA stock standards were diluted to $10 \mathrm{mg} / \mathrm{mL}$ in dimethyl sulfoxide and used for all analytical procedures. To measure plasma and urine OTA concentrations, pure OTA was diluted directly into blank biological matrices at the following concentrations to serve as analytical standards: $0.5,1,5,12.5,25,50$, and $100 \mu \mathrm{g} / \mathrm{mL}$ for plasma and $0.05,0.125,0.25$, $0.5,1$, and $5 \mu \mathrm{g} / \mathrm{mL}$ for urine. Unknown plasma samples were quantified against calibrators by spiking $2 \mu \mathrm{L}$ of either sample or calibrator into $50 \mu \mathrm{L}$ water with $0.1 \%$ formic acid containing d5OTA (internal standard) at a concentration of $400 \mathrm{ng} / \mathrm{mL}$. Both analytes were extracted from the aqueous phase by liquid-liquid extraction with $1.25 \mathrm{~mL}$ ethyl acetate. One milliliter of the organic phase was dried over air then reconstituted in $100 \mu \mathrm{L}$ of $20: 80$ acetonitrile:water with $0.1 \%$ formic acid prior to LC-MS/MS analysis. Unknown urine samples were quantified against calibrators by spiking $20 \mu \mathrm{L}$ of either sample or calibrator into $200 \mu \mathrm{L}$ water with $0.1 \%$ formic acid containing d5-OTA at a concentration of $50 \mathrm{ng} / \mathrm{mL}$. Both analytes were extracted from the aqueous phase by liquid-liquid extraction with $1 \mathrm{~mL}$ ethyl acetate. Eight hundred microliters of organic phase were dried over air then reconstituted in $100 \mu \mathrm{L}$ of 20:80 acetonitrile:water with $0.1 \%$ formic acid prior to LC-MS/MS analysis.

To measure tissue-bound OTA, a small slice of tissue was weighed and added to ice cold 80:20 methanol:water with $200 \mathrm{ng} / \mathrm{mL}$ d5-OTA at a ratio of $0.5 \mathrm{~mL}$ per $25 \mathrm{mg}$ tissue and homogenized using a rotary tissue grinder. Two hundred microliters were aliquoted, centrifuged for $10 \mathrm{~min}$ at $20,000 \times g$ and $4{ }^{\circ} \mathrm{C}$ to remove debris, then $100 \mu \mathrm{L}$ of supernatant was diluted with $1 \mathrm{~mL}$ water 
with $0.1 \%$ formic acid. Analytes were purified by liquid-liquid extraction with $1 \mathrm{~mL}$ ethyl acetate, vortexed, then centrifuged for $2 \mathrm{~min}$ at $300 \times \mathrm{g}$ to separate phases. A $500 \mu \mathrm{L}$ aliquot was dried over air then reconstituted with $200 \mu \mathrm{L} 20: 80$ acetonitrile:water with $0.1 \%$ formic acid prior to LC-MS/MS analysis. To quantify OTA in unknown tissue samples, blank tissue (kidney or liver) was homogenized in the same d5-OTA-spiked buffer at a ratio of $0.5 \mathrm{~mL}$ per $25 \mathrm{mg}$ tissue. The homogenate was then spiked with pure OTA and serially diluted to generate $31.25,62.5,125$, 250 , and $500 \mathrm{ng} / \mathrm{mL}$ calibrators and then processed in the same manner as unknown samples. Quantified unknown samples were converted to OTA mass per $25 \mathrm{mg}$ tissue based on the volume to tissue ratio.

Extracted samples were separated and quantified by LC-MS/MS using an Agilent UPLC system connected to a Sciex ${ }^{\circledR}$ QTrap $6500+^{\mathrm{TM}}$ triple quadrupole tandem mass spectrometer. Two microliters of all samples were injected onto a Luna Omega Polar C18 $1.6 \mu \mathrm{m}$ bead diameter UPLC column (Phenomenex) with $50 \times 2.1 \mathrm{~mm}$ dimensions using an autosampler. Analyte separation was achieved by binary gradient where mobile phase $A$ is water with $0.1 \%$ formic acid and mobile phase $B$ is acetonitrile with $0.1 \%$ formic acid as follows: column equilibration at $20 \%$ B for $1 \mathrm{~min}, 20$ to $90 \%$ B over $4 \mathrm{~min}, 90 \%$ B for $1 \mathrm{~min}, 90$ to $20 \%$ B over $0.5 \mathrm{~min}$, reequilibration at $20 \%$ B for $1 \mathrm{~min}$. All analytes were ionized for mass spectrometric detection using positive electrospray ionization with the following source parameters: $5.5 \mathrm{kV}$ electrospray voltage, $500{ }^{\circ} \mathrm{C}$ source temperature, 20 psi curtain gas, 25 psi nebulizer gas, and 25 psi turbo gas. OTA and d5-OTA were detected using multiple reaction monitoring using 404.2>239.0 and 409.2>239.0 mass transitions, respectively, with the following parameters: $80 \mathrm{~V}$ declustering potential, $10 \mathrm{~V}$ entrance potential, $37 \mathrm{eV}$ collision energy, $15 \mathrm{~V}$ collision cell exit potential. The LC-MS/MS system was operated using Analyst ${ }^{\mathrm{TM}}$ software and analyte peak areas were integrated and quantified using MultiQuant ${ }^{\mathrm{TM}}$ software. All calibration curves were computed 
using linear regression with $1 / x^{2}$ weighting with $R^{2} \geq 0.99$; all unknown values for each biological matrix or tissue fell within the limits of each respective calibration curve.

\section{Surrogate Peptide Quantification of OTA Transporters}

Kidney and liver tissue membrane fractions were prepared by ultracentrifugation, digested with trypsin, then unique surrogate peptides of OTA transporters were quantified by LC-MS/MS as previously described (Jilek, Frost, Jacobus, He, Toth, Goedken and Cherrington, 2021). Briefly, tissue was homogenized on ice in $10 \mathrm{mM}$ tris buffer with protease inhibitor (Pierce), centrifuged to remove debris at $8,000 \times g$ for $10 \mathrm{~min}$. Supernatants were collected and membrane fractions were pelleted by ultracentrifugation at $100,000 \times g$ for $1 \mathrm{~h}$ at $4{ }^{\circ} \mathrm{C}$. The pellet was rinsed then reconstituted with $10 \mathrm{mM}$ tris buffer $(\mathrm{pH} 8.0)$, then $300 \mu \mathrm{g}$ of protein was diluted into digestion buffer containing $3.7 \%(\mathrm{w} / \mathrm{v})$ sodium deoxycholate $100 \mathrm{mM}$ ammonium bicarbonate. Protein was reduced at $95^{\circ} \mathrm{C}$ for $5 \mathrm{~min}$ with $6 \mathrm{mM}$ dithiothreitol, alkylated at room temperature in the dark with $15 \mathrm{mM}$ iodoacetamide, the alkylation reaction was quenched with $20 \mathrm{mM}$ dithiothreitol, then peptides were digested with trypsin/Lys-C (Pierce) at $37{ }^{\circ} \mathrm{C}$ overnight using an enzyme:substrate ratio of $1: 100$. The next day, the digestion reaction was quenched with $0.4 \%$ formic acid containing heavy-labeled peptide standards (Table 1) and centrifuged for 30 min at 20,000 x $g$ and $4{ }^{\circ} \mathrm{C}$ to remove detergent. Peptides were extracted and concentrated from the supernatants by strong cation exchange solid phase extraction (1 mg MCX cartridges, Waters, Inc.) following the manufacturer instructions. Eluted peptides were dried using a vacuum centrifuge, reconstituted in $50 \mu \mathrm{L}$ starting LC-MS/MS mobile phase conditions, and $10 \mu \mathrm{L}$ was injected onto an Acquity ${ }^{\mathrm{TM}}$ UPLC HSS C18 column (Waters, Inc.) using an Agilent $\circledast$ autosampler, then separated by binary gradient flow using water and acetonitrile with $0.1 \%$ formic acid as previously described (Jilek, Frost, Jacobus, He, Toth, Goedken and Cherrington, 2021). Surrogate tryptic peptides were then detected on a Sciex® QTrap 6500+ ${ }^{\mathrm{TM}}$ triple quadrupole tandem mass spectrometer using multiple reaction monitoring (Table 1). Peak areas were 
integrated and quantified against pure peptide standards (Table 1) and protein abundance was converted to $\mathrm{pmol} / \mathrm{mg}$ protein using the following equation:

$$
\text { Protein Abundance }\left(\frac{\text { pmol }}{m g \text { Protein }}\right)=\frac{\text { Surrogate Peptide }(p g)}{\text { Peptide } M W\left(\frac{g}{m o l}\right)} \times \frac{1}{\text { Peptide Input }(m g)}
$$

\section{Pharmacokinetics Modeling and Data Analysis}

Plasma OTA pharmacokinetic parameters were derived by the area under the plasma concentration-time curve (AUC) method using Phoenix WinNonlin ${ }^{\mathrm{TM}}$ version 8.1 (Certara, Inc.). Renal excretion as a percent of dose was calculated by the percent of total amount of OTA eliminated into the urine over $72 \mathrm{~h}$ to the bolus dose by oral gavage. Grouped analysis represents mean values \pm standard deviation. Means were compared using two-tailed Student's t-test or analysis of variance (ANOVA) where appropriate (GraphPad ${ }^{\text {TM }}$ Prism 9.0); comparisons were considered significantly different when $P<0.05$.

\section{Histopathology}

Kidney samples were fixed in $10 \%$ neutral-buffered formalin prior to routine processing and paraffin embedding. Tissue sections $(5 \mu \mathrm{m})$ were stained with hematoxylin and eosin and examined/analyzed by a board-certified veterinary pathologist. Renal sections were examined for necrosis, degeneration, vacuolation, regeneration, tubular dilation, epithelial cell loss and glomerular changes. Semiquantitiative severity scores were as follows: 0 , none; 1 , minimal with less than $10 \%$ effected; 2 , mild with 10 to $25 \%$ effected; 3 , moderate with 25 to $40 \%$ effected; 4 , marked with 40 to $50 \%$ effected; and 5 , sever with over $50 \%$ effected.

\section{Results}

NASH Mice Display Reduced OTA-Associated Nephrotoxicity 
Following a single $12.5 \mathrm{mg} / \mathrm{kg}$ p.o. bolus dose of OTA, healthy and NASH mice lost $7.00 \% \pm$ $2.63 \%$ and $15.68 \pm 1.20 \%$ of baseline bodyweight, respectively, suggesting that OTA may be generally less toxic in NASH mice (Figure 1). At sacrifice, both kidney and liver masses of control mice decreased by approximately $12 \%$ and $30 \%$ more than that of $\mathrm{NASH}$ mice treated with the same dose of OTA per kg bodyweight (Figure 1). These findings were supported by histopathological lesions in the kidney, but not in liver of OTA-exposed treatment groups. Specifically, necrosis scores increased significantly from minimal (score of 1 ) in NASH mice to mild (score of 2) in healthy mice (Figures 2 and 3). Similar significant histopathological trends were observed for the endpoint of proximal convoluted tubule cell vacuolation with reduced findings in the NASH/OTA group when compared to the healthy/OTA group. (Figure 3). Furthermore, degeneration of proximal convoluted tubule epithelial cells was decreased where half of the NASH mice presented with no degenerative lesions, whereas all healthy mice exhibited at least mild degenerative lesions in response to OTA. (Figure 3). There were no histopathological findings in OTA-naïve mice.

\section{OTA Renal Excretion Increases in NASH Mice}

To probe the differential nephrotoxicity induced by OTA in healthy and NASH mice, tissue distribution and OTA elimination was compared between both groups. While individual mean plasma OTA concentrations over 72 hours did not vary significantly between groups, the plasma concentration-time curve trended upwards in the NASH mice, relative to healthy mice (Figure 4). This was confirmed by a significant increase in dose normalized plasma $A_{U C}$ last from $5.65 \pm$ $1.10 \mathrm{mg} \cdot \mathrm{h} / \mathrm{mL} / \mathrm{mg}$ OTA in healthy animals to $7.95 \pm 0.61 \mathrm{mg} \cdot \mathrm{h} / \mathrm{mL} / \mathrm{mg}$ OTA (Table 2). However, the observed dose-normalized $C_{\max }$ in both groups was nearly identical at approximately 200 $\mu \mathrm{g} / \mathrm{mL} / \mathrm{mg}$ OTA and the elimination half-life did not change significantly either. Notably, these changes were reflected in an approximately $33 \%$ decrease in apparent volume of distribution, suggesting that OTA may be accumulating in tissues at a greater rate in healthy animals (Table 
2). As such, kidney- and liver-bound OTA increased significantly in healthy animals by approximately $30 \%$ in both tissues, relative to $\mathrm{NASH}$ animals (Figure 5).

While systemic rates of elimination did not vary between both groups, the cumulative percent of OTA eliminated into the urine robustly increased in NASH animals, and this difference became significant at $48 \mathrm{~h}$ post dose (Figure 4). At sacrifice, the total amount of OTA eliminated into the urine in NASH mice was nearly two-fold higher than in healthy mice (Table 2). This change was reflected in a significant increase in renal excretion from $5.55 \pm 0.37 \%$ in healthy mice to $13.11 \pm$ $3.10 \%$ in NASH mice (Table 2).

\section{NASH Induces Changes to OTA Transporters}

Given changes to renal excretion and disposition of OTA, renal and hepatic transporter expression was quantified to probe a possible molecular mechanism for this difference. Using a surrogate peptide LC-MS/MS method, known organic anion transporters were absolutely quantified from renal and hepatic membrane fractions (Figure 6). Notably, all OAT isoforms in the kidney decreased to various degrees and OAT2 in the liver decreased modestly in the NASH mice. Basolateral renal OTA uptake transporters, OAT1 and OAT3, decreased in NASH mice from $0.37 \pm 0.07$ to $0.19 \pm 0.09 \mathrm{pmol} / \mathrm{mg}$ protein and $1.02 \pm 0.43$ to $0.29 \pm 0.13 \mathrm{pmol} / \mathrm{mg}$ protein, respectively. Expression of OAT2 also decreased in the kidney and liver of NASH mice from $2.20 \pm 0.19$ to $1.22 \pm 0.46 \mathrm{pmol} / \mathrm{mg}$ protein and $3.03 \pm 0.41$ to $2.39 \pm 0.30 \mathrm{pmol} / \mathrm{mg}$ protein, respectively. Lastly, NASH mice displayed a robust decrease of the apically-expressed renal OAT5 transporter from $1.12 \pm 0.09$ to $0.49 \pm 0.19 \mathrm{pmol} / \mathrm{mg}$ protein, relative to healthy mice. Interestingly, P-gp increased significantly in renal tissue of NASH mice from an extremely low abundance to approximately $1.25 \mathrm{pmol} / \mathrm{mg}$ protein, suggesting that it may be induced in this tissue during NASH (Figure 6). Furthermore, renal MRP2 decreased by approximately half in NASH mice, relative to healthy, although hepatic MRP2 increased modestly in NASH mice. 
Lastly, BCRP, MRP3, and MRP4 which facilitate active organic anion export did not change between NASH and healthy animals.

\section{Discussion}

The current understanding of the mechanism of OTA renal elimination is proposed to be the sum of active OAT1- and OAT3-mediated secretion into the proximal tubule cells and glomerular filtration of unbound OTA, less any OAT2- and OAT5-mediated uptake from the filtrate back into the proximal convoluted tubule cell (Anzai, Jutabha and Endou, 2010). Given the dramatic decreases of all OAT transporters (Figure 6), these data suggest that renal secretion and reabsorption are functionally limited in NASH mice, reducing the exposure of the proximal tubule cell to OTA. Additionally, glomerular filtration removes the small fraction of OTA that is unbound to plasma proteins, and our data suggest that the OAT2 and 5 decreases in $\mathrm{NASH}$ animals (Figure 6) reduces the amount reabsorbed. As such, we observed an increase in the cumulative OTA eliminated into the urine (Figure 4), reflected in a significant increase in OTA renal excretion (Table 2). These observations are further supported by evidence that less OTA is bound to renal tissue in NASH mice, relative to healthy mice (Figure 5), and that this also manifests in significant decreases in nephrotoxic lesions in NASH mice (Figure 1-2). Taken together, these findings support a mechanistic protective effect of $\mathrm{NASH}$-induced renal transporter phenoconversion.

OAT2 and 5 function is bidirectional (Anzai, Jutabha, Enomoto, Yokoyama, Nonoguchi, Hirata, Shiraya, He, Cha, Takeda, Miyazaki, Sakata, Tomita, Igarashi, Kanai and Endou, 2005), consistent with other OAT isoforms, and in theory may function to secrete OTA into the filtrate via transepithelial transport following OAT1 and 3 uptake, in addition to reabsorption from the filtrate. As such, reduced OAT 2 and 5 expression in NASH mice (Figure 6) exposed to OTA could either 1) sequester OTA that has been taken up by basolateral OATs in proximal convoluted tubule cells, or 2) have a reduced capacity to reabsorb OTA from the tubular lumen. 
Although the data presented in this work do not prove the directionality of OAT2/5-mediated net OTA transport, these data suggest that OAT2/5 reductions induced by NASH reduces reabsorption into the proximal convoluted tubule cells.

NASH mice in this study demonstrated a significant decrease in basolateral OAT1/3 (Figure 6), which may reduce proximal tubule cell disposition, as observed (Figure 5). This may contribute to the observed reduction in nephrotoxicity in NASH mice (Figure 3), as the plasma AUC also increased modestly (Table 2). However, average plasma concentrations at specific timepoints did not significantly differ between NASH and healthy animals (Figure 4), nor did the rate of plasma OTA clearance (Table 2). Additionally, OTA is extensively plasma protein bound, reducing the available pool of systemic OTA available for glomerular filtration and transportmediated secretion (Ringot, Chango, Schneider and Larondelle, 2006). Given the long elimination half-life in most species, including mice used in this study ( $\mathrm{t}_{1 / 2} \sim 50-60 \mathrm{~h}$, Table 2), it is unlikely that renal proximal tubule cells can accumulate a significant concentration gradient to shift the transport equilibrium to favor export of OTA. As such, these data, in addition to OTA physiochemical properties, suggest that reabsorption is a major driver of OTA nephrotoxicity.

Transport of OTA across biological barriers is somewhat well-understood, however, significant species differences exist. Oat5 is one of the primary apical OTA transporters, although it is not expressed in humans; likewise, OAT4 has significant substrate overlap with Oat5, including OTA, and is also expressed on the luminal membrane, but is not expressed in rodents (Nigam, Bush, Martovetsky, Ahn, Liu, Richard, Bhatnagar and Wu, 2015; Ivanyuk, Livio, Biollaz and Buclin, 2017). As such, while rodent Oat5 and human OAT4 share functional similarities, they are not true orthologues. Furthermore, while OAT2 expression is very low in the human kidney, our data suggest that absolute expression is appreciable in the mouse kidney (Figure 2 and (Basit, Radi, Vaidya, Karasu and Prasad, 2019)). Additionally, OAT2 expression in humans is localized to the basolateral membrane, whereas in rodents it is localized to the apical 
membrane (Ljubojevic, Balen, Breljak, Kusan, Anzai, Bahn, Burckhardt and Sabolic, 2007; Nigam, Bush, Martovetsky, Ahn, Liu, Richard, Bhatnagar and Wu, 2015). Thus, while OAT4/5dependent OTA reabsorption from the luminal filtrate is somewhat well studied, this species difference in rodents is not. Lastly, new OTA renal transporters are being identified, including human sodium/phosphate cotransporter 4 (hNPT4) (Jutabha, Anzai, Hayashi, Domae, Uchida, Endou and Sakurai, 2011); however, functional orthologues in rodents have not been identified to date.

Taken together, these results provide evidence suggesting that NASH-mediated decreases in several OAT isoforms reduce the kidney's capacity to accumulate OTA in an FFD/TH mouse model of $\mathrm{NASH}$, thus reducing its nephrotoxicity. Additionally, as a major mechanism of organic anion clearance, NASH-induced disruptions to OAT expression likely affects renal elimination of other drugs and toxicants with similar physiochemical profiles. As such, this work highlights the importance of changes to reabsorption pathways, in addition to filtration and secretion, during $\mathrm{NASH}$, which may influence xenobiotic clearance, efficacy, or toxicity.

\section{Authorship contributions}

Participated in research design: JLJ, SHW, NJC

Conducted experiments: JLJ, KLF, SM, CMM, MG

Contributed new reagents or analytic tools: JLJ

Performed data analysis: JLJ, MG

Wrote or contributed to the writing of the manuscript: JLJ, KLF, SM, CMM, MG, SHW, NJC

\section{Figure Legends}

Figure 1. NASH animals administered $12.5 \mathrm{mg} / \mathrm{kg}$ OTA presented with less bodyweight and tissue loss after $\mathbf{7 2} \mathrm{h}$ compared to healthy mice. Individual bodyweights were measured 
at $\mathrm{t}=0$ and $\mathrm{t}=72 \mathrm{~h}$ study time and change in bodyweight was determined relative to $\mathrm{t}=0$. Kidney and liver masses were measured at sacrifice and normalized to bodyweight. Mean values \pm SD (n=4 mice/group) were compared by unpaired two-tailed Student's t-test where * indicates $P<$ 0.05 .

Figure 2. Proximal tubule lesions are more prevalent in OTA-exposed healthy mice than OTA-exposed NASH mice. Kidney slices were obtained from OTA-exposed and OTA-naïve mice in both healthy and NASH cohorts. Necrotic (red circles), degenerative (yellow boxes), and cell loss lesions (green boxes) were more frequently observed in the proximal convoluted tubules of healthy OTA-exposed mice than in NASH OTA-exposed mice. Formalin fixed and paraffin embedded kidney slides were stained with hematoxylin and eosin; representative images were captured at 200x magnification.

Figure 3. Necrotic and degenerative lesions and proximal convoluted tubule cell vacuolation are more prevalent in healthy OTA-exposed mice than NASH OTA-exposed mice. Significant increases in necrosis, degeneration, and proximal convoluted tubule (PCT) vacuolation were observed in healthy OTA-exposed animals, relative to NASH OTA-exposed animals. No histomorphological findings were observed in the kidney of OTA-naïve mice. Points represent individual animals and horizontal bars represent mean values \pm SD. Mean values were compared by one-way ANOVA with Sidak's post-hoc test where * indicates $P<0.05$.

Figure 4. NASH increases urinary OTA excretion but does not significantly alter plasma OTA concentrations. Plasma OTA concentrations over $72 \mathrm{~h}$ were measured by LC-MS/MS and compared between NASH and healthy groups and no significant changes were observed between both groups (right panel). OTA excreted into the urine was measured by LC-MS/MS throughout the study and the mass of OTA recovered in the urine was calculated as a percentage of the bolus dose. Data points represent mean values \pm SD of $n=4$ animals/group and were compared by two-way ANOVA with Sidak's post-hoc test where * indicates $P<0.05$. 
Figure 5. NASH reduces kidney and liver disposition of a single OTA exposure. After $72 \mathrm{~h}$, the relative amount of OTA in kidney and liver tissue was measured by LC-MS/MS as described in Methods. Data points represent individual animal values and horizontal bars represent mean values $\pm S D$ of $n=4$ animals/group. Mean values were compared by unpaired two-tailed Student's t-test where * indicates $P<0.05$.

Figure 6. ОTA uptake transporter expression is altered in NASH mice. Transporter expression in liver and kidney tissue was evaluated by quantifying surrogate peptides. NASH animals showed significant decreases in basolateral OAT1 and 3 and apical OAT2 and 5 OTA uptake transporter expression. No significant changes were found in BCRP, MRP3, or MRP4 expression which also catalyze OTA efflux, whereas renal P-gp and hepatic MRP2 expression increased. Data points represent individual animal values and horizontal bars represent mean values $\pm S D$ of $n=4$ animals/group. Mean values were compared by unpaired two-tailed Student's t-test where * indicates $P<0.05$.

\section{Tables}

Table 1. OTA transporter surrogate peptides and multiple reaction monitoring method used for this study. Membrane protein fractions were digested with trypsin to quantify transporter expression. Multiple reaction monitoring transitions used for detection are listed as doubly-charged parent ion (Q1) and singly charged fragment ion (Q3) used for quantification. * Indicates ${ }^{13} \mathrm{C} /{ }^{16} \mathrm{~N}$ heavy isotope labeled amino acid internal standards (IS). RT indicates retention time for liquid chromatography method.

\begin{tabular}{llllll}
\hline Protein & $\begin{array}{l}\text { Peptide } \\
\text { Sequence }\end{array}$ & IS & $\begin{array}{l}\text { RT } \\
(\mathrm{min})\end{array}$ & $\begin{array}{l}\text { Q1 } \\
{[\mathrm{M}+2 \mathrm{H}]^{2+}(\mathrm{Da})}\end{array}$ & $\begin{array}{l}\text { Q3 } \\
{[\mathrm{M}+\mathrm{H}]^{+}(\mathrm{Da})}\end{array}$ \\
\hline P-gp & IATEAIENFR & BCRP-H & 15.8 & 582.3 & 979.5 \\
BCRP & ENLQFSAAR & BCRP-H & 16.5 & 574.8 & 792.4 \\
MRP2 & GINLSGGQK & MRP2-H & 9.8 & 437.2 & 703.4 \\
MRP3 & QGELQLLR & MRP2-H & 10.0 & 366.2 & 501.3
\end{tabular}




\begin{tabular}{llllll} 
MRP4 & APVLFFDR & MRP4-H & 19.9 & 482.8 & 697.4 \\
OAT1 & TSLAVLGK & OAT1-H & 14.0 & 394.7 & 600.4 \\
OAT2 & VGGFGPFQLR & MRP4-H & 20.4 & 539.3 & 864.5 \\
OAT3 & DITSAK & MRP2-H & 4.8 & 317.7 & 406.2 \\
OAT5 & ILSQDDLLR & BCRP-H & 16.1 & 536.8 & 846.4 \\
OATP4C1 & DFPTAVK & OAT1-H & 12.2 & 389.2 & 515.3 \\
MRP2-H & GINL*SGGQK & --- & 9.8 & 440.7 & 710.4 \\
MRP4-H & TSLA*VLGK & --- & 20.4 & 486.3 & 704.4 \\
BCRP-H & ENLQFSA*ALR & --- & 16.5 & 576.9 & 668.4 \\
OAT1-H & TSLA*VLGK & --- & 14.0 & 396.7 & 491.3 \\
\hline
\end{tabular}


Table 2. Pharmacokinetic parameters in healthy and NASH rats administered $12.5 \mathrm{mg} / \mathrm{kg}$ OTA. Mean values $\pm S D$ were compared by unpaired two-tailed Student's t-test where * indicates $P<0.05 . \mathrm{t}_{1 / 2}$, elimination half-life; $\mathrm{C}_{\max }$, maximal plasma concentration; $A \mathrm{UC}_{\text {last }}$, area under the plasma concentration-time curve measured from 0 to $72 \mathrm{~h}$; $\mathrm{D}$, dose; $\mathrm{V}_{\mathrm{z}} / \mathrm{F}$, apparent volume of distribution; CL/F, apparent systemic clearance; $A_{e}$, amount excreted into urine over 72 h.

\begin{tabular}{llllllll}
\hline & $\begin{array}{l}\mathbf{t}_{1 / 2} \\
\mathrm{~h}\end{array}$ & $\begin{array}{l}\mathbf{C}_{\mathrm{max}} / \mathbf{D} \\
\mu \mathrm{g} \cdot \mathrm{mL}^{-} \\
1 \cdot \mathrm{mg}^{-1}\end{array}$ & $\begin{array}{l}\mathbf{A U C}_{\text {last }} / \mathbf{D} \\
\mathrm{mg} \cdot \mathrm{h} \cdot \mathrm{ml}^{-} \\
1 \cdot \mathrm{mg}^{-1}\end{array}$ & $\begin{array}{l}\mathbf{V}_{\mathbf{z}} / \mathbf{F} \\
\mathrm{mL}\end{array}$ & $\begin{array}{l}\mathbf{C L} / \mathbf{F} \\
\mathrm{mL} \cdot \mathrm{h}^{-1}\end{array}$ & $\begin{array}{l}\mathbf{A}_{\mathrm{e}} \\
\mu \mathrm{g}\end{array}$ & $\begin{array}{l}\mathbf{A}_{\mathrm{e}} \% \text { of } \\
\mathrm{dose}\end{array}$ \\
\hline Control & $62.46 \pm$ & $199.80 \pm$ & $5.65 \pm$ & $8.28 \pm$ & $0.10 \pm$ & $24.41 \pm$ & $5.55 \pm$ \\
& 17.04 & 79.25 & 1.10 & 1.51 & 0.03 & 1.74 & 0.37 \\
NASH & $53.17 \pm$ & $196.90 \pm$ & $\mathbf{7 . 9 5} \pm$ & $\mathbf{5 . 4 4} \pm$ & $0.08 \pm$ & $\mathbf{4 0 . 0 7 \pm}$ & $\mathbf{1 3 . 1 1 \pm}$ \\
& 19.38 & 52.51 & $\mathbf{0 . 6 1 *}$ & $\mathbf{0 . 4 1}{ }^{*}$ & 0.02 & $\mathbf{9 . 1 9}^{*}$ & $\mathbf{3 . 1 0}^{*}$ \\
\hline
\end{tabular}




\section{References}

Al-Anati L and Petzinger E (2006) Immunotoxic activity of ochratoxin A. J Vet Pharmacol Ther 29:79-90.

Anzai N, Jutabha P, and Endou H (2010) Molecular mechanism of ochratoxin a transport in the kidney. Toxins (Basel) 2:1381-1398.

Anzai N, Jutabha P, Enomoto A, Yokoyama H, Nonoguchi H, Hirata T, Shiraya K, He X, Cha SH, Takeda M, Miyazaki H, Sakata T, Tomita K, Igarashi T, Kanai $\mathrm{Y}$, and Endou $\mathrm{H}$ (2005) Functional characterization of rat organic anion transporter 5 (Slc22a19) at the apical membrane of renal proximal tubules. J Pharmacol Exp Ther 315:534-544.

Basit A, Radi Z, Vaidya VS, Karasu M, and Prasad B (2019) Kidney Cortical Transporter Expression across Species Using Quantitative Proteomics. Drug Metabolism and Disposition 47:802-808.

Bui-Klimke TR and Wu F (2015) Ochratoxin A and human health risk: a review of the evidence. Critical reviews in food science and nutrition 55:1860-1869.

Canet MJ and Cherrington NJ (2014) Drug disposition alterations in liver disease: extrahepatic effects in cholestasis and nonalcoholic steatohepatitis. Expert Opin Drug Metab Toxicol 10:1209-1219.

Canet MJ, Hardwick RN, Lake AD, Dzierlenga AL, Clarke JD, Goedken MJ, and Cherrington NJ (2015) Renal xenobiotic transporter expression is altered in multiple experimental models of nonalcoholic steatohepatitis. Drug Metab Dispos 43:266-272.

Castegnaro M, Canadas D, Vrabcheva T, Petkova-Bocharova T, Chernozemsky IN, and PfohlLeszkowicz A (2006) Balkan endemic nephropathy: role of ochratoxins A through biomarkers. Mol Nutr Food Res 50:519-529.

Cha SH, Sekine T, Kusuhara H, Yu E, Kim JY, Kim DK, Sugiyama Y, Kanai Y, and Endou H (2000) Molecular Cloning and Characterization of Multispecific Organic Anion 
Transporter 4 Expressed in the Placenta*. Journal of Biological Chemistry 275:45074512.

Clarke JD and Cherrington NJ (2015) Nonalcoholic steatohepatitis in precision medicine: Unraveling the factors that contribute to individual variability. Pharmacol Ther 151:99106.

Clarke JD, Hardwick RN, Lake AD, Lickteig AJ, Goedken MJ, Klaassen CD, and Cherrington NJ (2014) Synergistic interaction between genetics and disease on pravastatin disposition. $J$ Hepatol 61:139-147.

Dzierlenga AL and Cherrington NJ (2018) Misregulation of membrane trafficking processes in human nonalcoholic steatohepatitis. J Biochem Mol Toxicol 32:e22035.

Gekle M, Pollock CA, and Silbernagl S (1995) Time- and concentration-dependent biphasic effect of ochratoxin A on growth of proximal tubular cells in primary culture. $J$ Pharmacol Exp Ther 275:397-404.

Gekle M and Silbernagl S (1993) Mechanism of ochratoxin A-induced reduction of glomerular filtration rate in rats. Journal of Pharmacology and Experimental Therapeutics 267:316321.

Gekle M and Silbernagl S (1994) The Role of the Proximal Tubule in Ochratoxin A Nephrotoxicity in vivo: Toxodynamic and Toxokinetic Aspects. Kidney and Blood Pressure Research 17:40-49.

Hagos $Y$ and Wolff NA (2010) Assessment of the role of renal organic anion transporters in drug-induced nephrotoxicity. Toxins (Basel) 2:2055-2082.

Hardwick RN, Fisher CD, Canet MJ, Scheffer GL, and Cherrington NJ (2011) Variations in ATPbinding cassette transporter regulation during the progression of human nonalcoholic fatty liver disease. Drug Metab Dispos 39:2395-2402.

Heussner AH and Bingle LE (2015) Comparative Ochratoxin Toxicity: A Review of the Available Data. Toxins (Basel) 7:4253-4282. 
Huff WE, Wyatt RD, and Hamilton PB (1975) Nephrotoxicity of dietary ochratoxin A in broiler chickens. Appl Microbio/ 30:48-51.

Huo X and Liu K (2018) Renal organic anion transporters in drug-drug interactions and diseases. Eur J Pharm Sci 112:8-19.

Ivanyuk A, Livio F, Biollaz J, and Buclin T (2017) Renal Drug Transporters and Drug Interactions. Clin Pharmacokinet 56:825-892.

Jilek JL, Frost KL, Jacobus KA, He W, Toth EL, Goedken M, and Cherrington NJ (2021) Altered cisplatin pharmacokinetics during nonalcoholic steatohepatitis contributes to reduced nephrotoxicity. Acta Pharmaceutica Sinica $B$.

Jung KY, Takeda M, Kim DK, Tojo A, Narikawa S, Yoo BS, Hosoyamada M, Cha SH, Sekine T, and Endou $\mathrm{H}$ (2001) Characterization of ochratoxin A transport by human organic anion transporters. Life Sci 69:2123-2135.

Jutabha P, Anzai N, Hayashi K, Domae M, Uchida K, Endou H, and Sakurai H (2011) A novel human organic anion transporter NPT4 mediates the transport of ochratoxin A. $J$ Pharmacol Sci 116:392-396.

Laho T, Clarke JD, Dzierlenga AL, Li H, Klein DM, Goedken M, Micuda S, and Cherrington NJ (2016) Effect of nonalcoholic steatohepatitis on renal filtration and secretion of adefovir. Biochem Pharmacol 115:144-151.

Limonciel A and Jennings $P$ (2014) A Review of the Evidence that Ochratoxin A Is an Nrf2 Inhibitor: Implications for Nephrotoxicity and Renal Carcinogenicity. Toxins 6.

Ljubojevic M, Balen D, Breljak D, Kusan M, Anzai N, Bahn A, Burckhardt G, and Sabolic I (2007) Renal expression of organic anion transporter OAT2 in rats and mice is regulated by sex hormones. Am J Physiol Renal Physiol 292:F361-372.

Malir F, Ostry V, Pfohl-Leszkowicz A, Malir J, and Toman J (2016) Ochratoxin A: 50 Years of Research. Toxins 8:191. 
Mally A, Völkel W, Amberg A, Kurz M, Wanek P, Eder E, Hard G, and Dekant W (2005) Functional, Biochemical, and Pathological Effects of Repeated Oral Administration of Ochratoxin A to Rats. Chemical Research in Toxicology 18:1242-1252.

Masereeuw R and Russel FG (2001) Mechanisms and clinical implications of renal drug excretion. Drug Metab Rev 33:299-351.

Meier Y, Pauli-Magnus C, Zanger UM, Klein K, Schaeffeler E, Nussler AK, Nussler N, Eichelbaum M, Meier PJ, and Stieger B (2006) Interindividual variability of canalicular ATP-binding-cassette (ABC)-transporter expression in human liver. Hepatology 44:6274.

Mooij MG, Schwarz UI, de Koning BA, Leeder JS, Gaedigk R, Samsom JN, Spaans E, van Goudoever JB, Tibboel D, Kim RB, and de Wildt SN (2014) Ontogeny of human hepatic and intestinal transporter gene expression during childhood: age matters. Drug Metab Dispos 42:1268-1274.

Nakanishi T and Tamai I (2012) Genetic polymorphisms of OATP transporters and their impact on intestinal absorption and hepatic disposition of drugs. Drug Metab Pharmacokinet 27:106-121.

Nigam SK, Bush KT, Martovetsky G, Ahn SY, Liu HC, Richard E, Bhatnagar V, and Wu W (2015) The organic anion transporter (OAT) family: a systems biology perspective. Physiol Rev 95:83-123.

Palumbo JD, O'Keeffe TL, Ho YS, and Santillan CJ (2015) Occurrence of ochratoxin a contamination and detection of ochratoxigenic Aspergillus species in retail samples of dried fruits and nuts. J Food Prot 78:836-842.

Pfohl-Leszkowicz A and Manderville RA (2007) Ochratoxin A: An overview on toxicity and carcinogenicity in animals and humans. Mol Nutr Food Res 51:61-99.

Prasad B, Evers R, Gupta A, Hop CE, Salphati L, Shukla S, Ambudkar SV, and Unadkat JD (2014) Interindividual variability in hepatic organic anion-transporting polypeptides and 
P-glycoprotein (ABCB1) protein expression: quantification by liquid chromatography tandem mass spectroscopy and influence of genotype, age, and sex. Drug Metab Dispos 42:78-88.

Ringot D, Chango A, Schneider YJ, and Larondelle Y (2006) Toxicokinetics and toxicodynamics of ochratoxin A, an update. Chem Biol Interact 159:18-46.

Santos L, Marín S, Sanchis V, and Ramos AJ (2009) Screening of mycotoxin multicontamination in medicinal and aromatic herbs sampled in Spain. Journal of the Science of Food and Agriculture 89:1802-1807.

Schwerdt G, Freudinger R, Mildenberger S, Silbernagl S, and Gekle M (1999) The nephrotoxin ochratoxin A induces apoptosis in cultured human proximal tubule cells. Cell Biology and Toxicology 15:405-415.

Sharma L, Gupta D, and Abdullah ST (2019) Thioacetamide potentiates high cholesterol and high fat diet induced steato-hepatitic changes in livers of C57BL/6J mice: A novel eight weeks model of fibrosing NASH. Toxicol Lett 304:21-29.

Shima JE, Komori T, Taylor TR, Stryke D, Kawamoto M, Johns SJ, Carlson EJ, Ferrin TE, and Giacomini KM (2010) Genetic variants of human organic anion transporter 4 demonstrate altered transport of endogenous substrates. Am J Physiol Renal Physiol 299:F767-775.

Shitara Y, Horie T, and Sugiyama Y (2006) Transporters as a determinant of drug clearance and tissue distribution. Eur J Pharm Sci 27:425-446.

Simon P, Godin M, and Fillastre JP (1996) Ochratoxin a: a new environmental factor which is toxic for the kidney? Nephrol Dial Transplant 11:2389-2391.

Stoev SD (2010) Studies on carcinogenic and toxic effects of ochratoxin A in chicks. Toxins 2:649-664. 
Urakami Y, Nakamura N, Takahashi K, Okuda M, Saito H, Hashimoto Y, and Inui K (1999) Gender differences in expression of organic cation transporter OCT2 in rat kidney. FEBS Lett 461:339-342.

van der Merwe KJ, Steyn PS, Fourie L, Scott DB, and Theron JJ (1965) Ochratoxin A, a toxic metabolite produced by Aspergillus ochraceus Wilh. Nature 205:1112-1113.

Xu YJ, Wang Y, Lu YF, Xu SF, Wu Q, and Liu J (2017) Age-associated differences in transporter gene expression in kidneys of male rats. Mol Med Rep 15:474-482.

Yonezawa A, Masuda S, Nishihara K, Yano I, Katsura T, and Inui K (2005) Association between tubular toxicity of cisplatin and expression of organic cation transporter rOCT2 (Slc22a2) in the rat. Biochem Pharmacol 70:1823-1831.

Yordanova P, Wilfried K, Tsolova S, and Dimitrov P (2010) Ochratoxin A and $\beta 2$-microglobulin in BEN patients and controls. Toxins 2:780-792.

Youngblood GL and Sweet DH (2004) Identification and functional assessment of the novel murine organic anion transporter Oat5 (Slc22a19) expressed in kidney. Am J Physiol Renal Physiol 287:F236-244.

\section{Footnotes}

This work was supported by the National Institutes of Health [R01ES028668] and [P30ES006694]. JLJ was supported by [T32ES007091].

The authors declare they have no conflicts of interest with the contents of this article. 
Figure 1

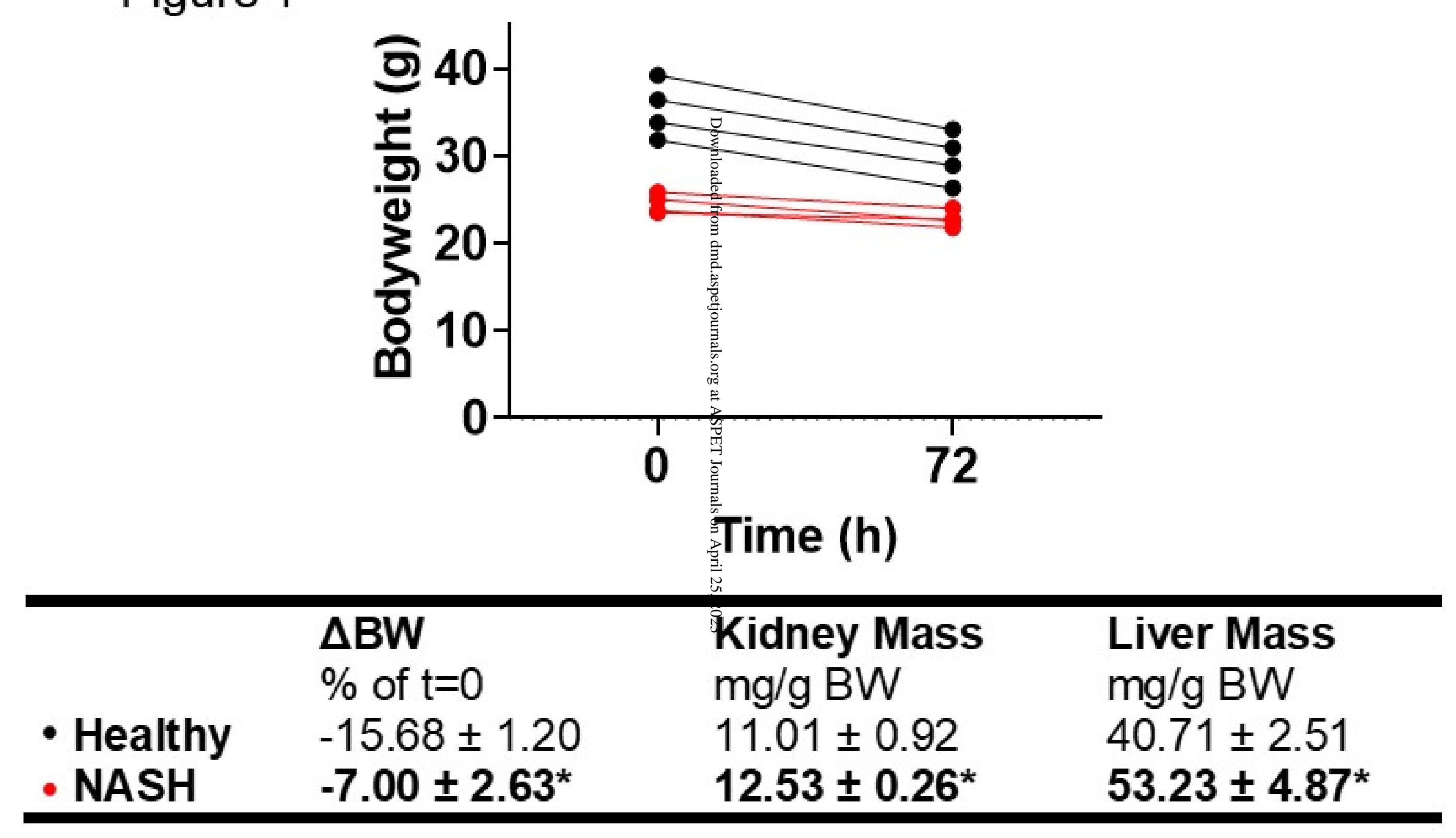


Figure 2

$\frac{\Phi}{Z}$

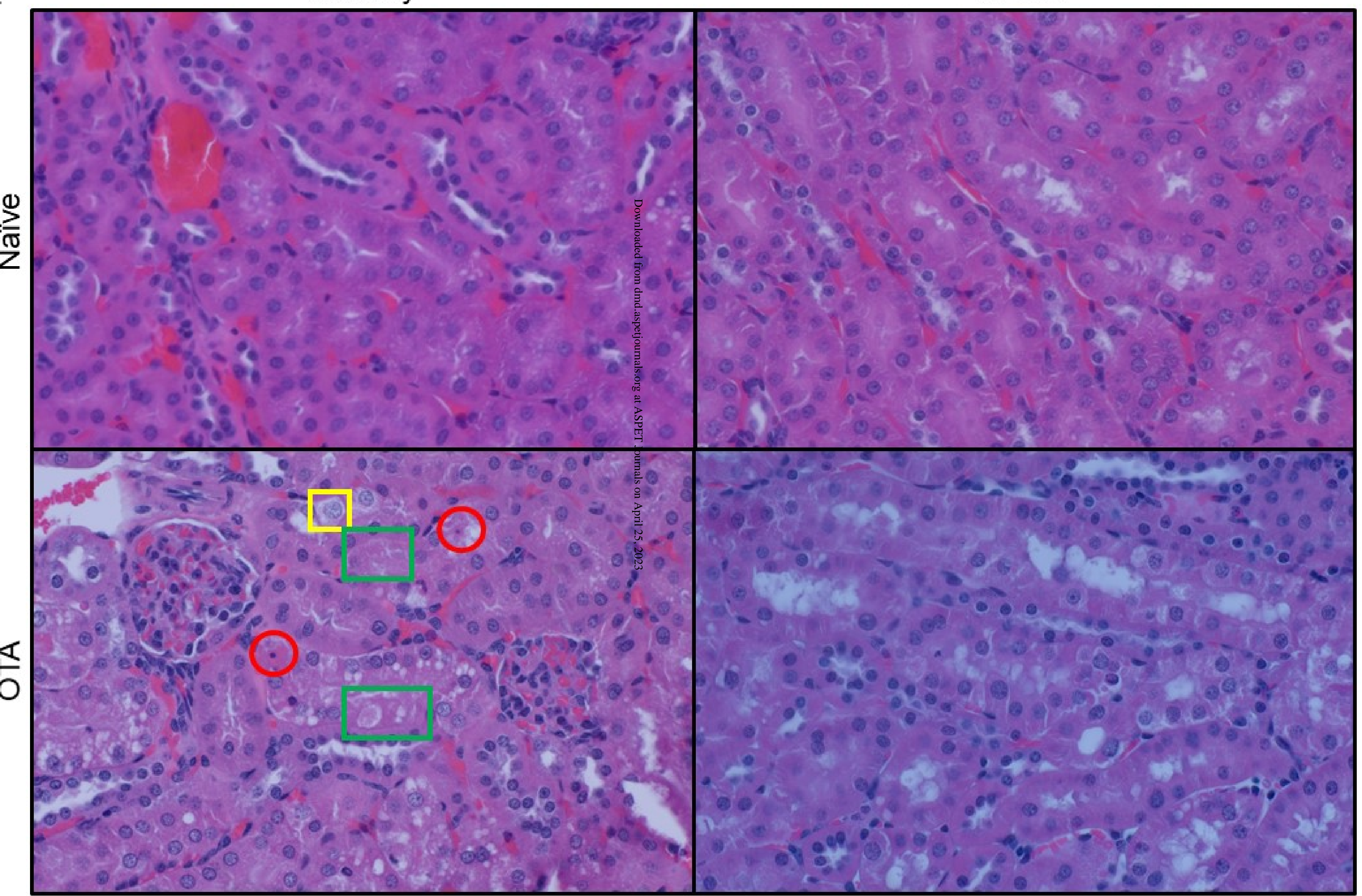


Figure 4
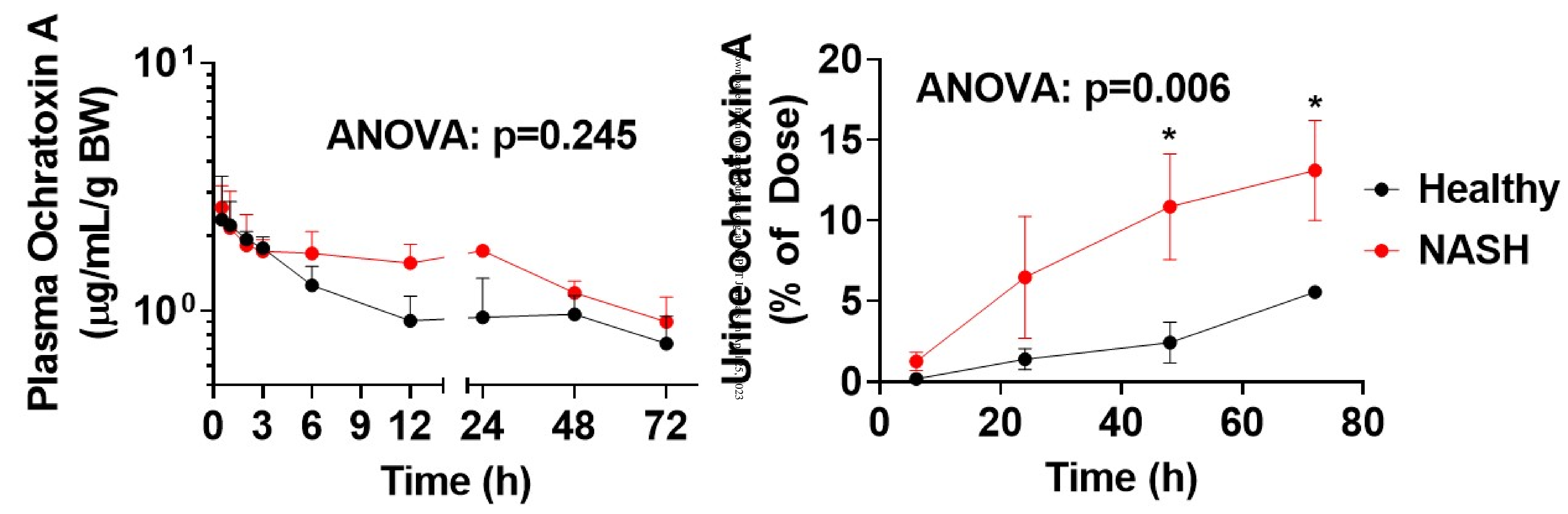
Figure 5
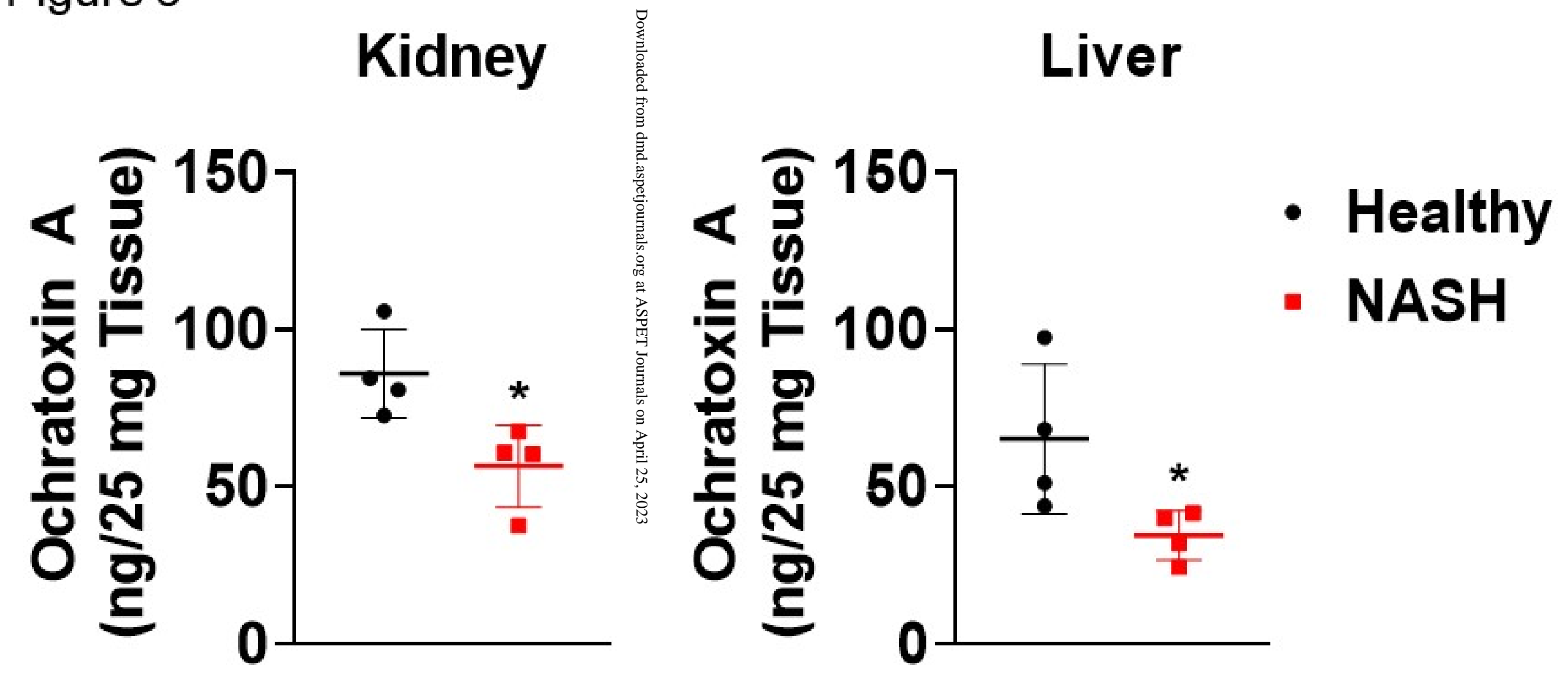
Figure 6
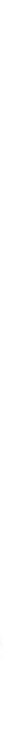

Tissue: Kidney

Liver Tissue: Kidney

Liver Tissue: Kidney Liver Tissue: Kidney Liver
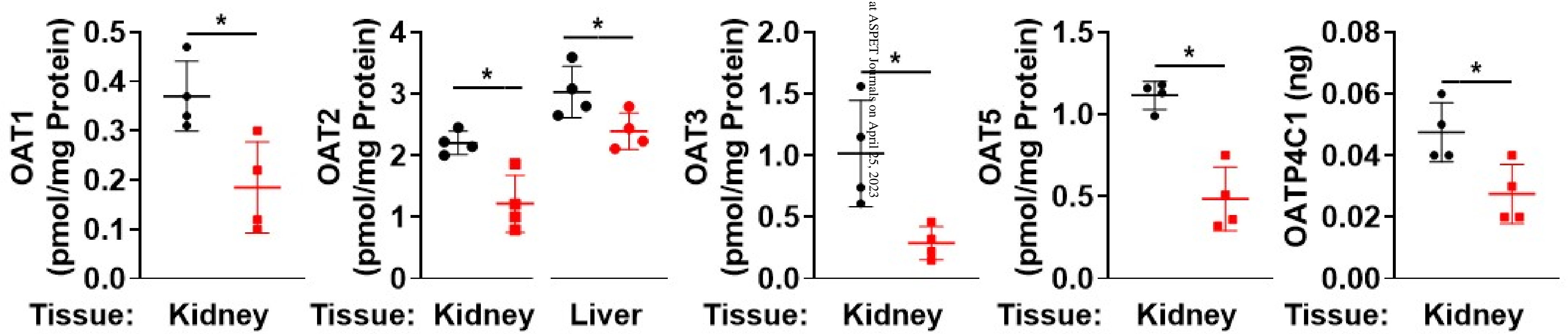

- Healthy

- NASH

Tissue: Kidney
0.00

Tissue: Kidney 